\title{
Cinema
}

\section{Simetrias, repetições e variações - a Missa em dó menor de Mozart em Um condenado à morte escapou, de Robert Bresson'}

\author{
Symmetries, repetitions and variations - Mozart's C-minor Mass in A man escaped \\ by Robert Bresson
}

Luíza BeATrIZ AMORIM MelO AlviM

Doutora em Comunicação pela Universidade Federal do Rio de Janeiro (UFRJ).

<luizabeatriz@yahoo.com>

\section{RESUMO}

Nos filmes do diretor francês Robert Bresson, especialmente naqueles da fase intermediária de sua carreira, foi comum o uso de música pré-existente do repertório clássico, e a distribuição de tais trechos musicais no filme possui analogias com a peça de origem. Em Um condenado à morte escapou (1956), partes instrumentais e corais oriundas do Kyrie da Missa em dó menor de Mozart estão distribuídas simetricamente ao longo do filme, evocando a simetria do próprio Classicismo de Mozart. A música também simboliza o caminho do protagonista, um prisioneiro durante a Segunda Guerra Mundial, que deve passar da solidão para a comunicação com os outros a fim de conseguir escapar.

Palavras-chave: Robert Bresson. Cinema. Música.

\section{ABSTRACT}

In the films of the french director Robert Bresson, especially in those from the intermediary phase of his career, preexistent classical music was commonly utilized and the distribution of these musical parts in the film guard analogies with the original piece. In A man escaped (1956), choral and instrumental parts from the Kyrie of Mozart's C-minor Mass are symmetrically distributed in the film, what recalls the very symmetry of Mozart's Classicism. The music also symbolizes the way of the main character, a prisoner during the Second World War, who has to pass from solitude to communication with the others in order to escape.

Keywords: Robert Bresson. Cinema. Music. 
cineasta francês Robert Bresson utilizou a música com bastante parcimônia em seus filmes. Característica comum a diretores que Claudia Gorbman (2007) reúne como responsáveis por "música de autor", Bresson lançou mão com frequência do repertório clássico pré-existente (clássico no sentido de "erudito", não de "Classicismo") para as incursões musicais de seus filmes.

No caso de seu quarto longa-metragem, Um condenado à morte escapou (1956), a parcimônia e o controle do diretor é tal, que a única trilha musical é constituída por trechos do Kyrie da Missa em dó menor K427, de Wolfgang Amadeus Mozart.

Em especial nos filmes da fase intermediária da carreira de Bresson - por exemplo, além de Um condenado à morte escapou, em Pickpocket (1959) e A grande testemunha (1966) - percebemos várias analogias entre o modo como os trechos musicais são distribuídos ao longo do filme e a forma da música pré-existente de que são oriundos, além de relações com aspectos referentes ao período a que as obras originais pertencem. No caso de Mozart, o Classicismo. Nesse período, a simetria é uma questão fundamental e ela se faz bastante presente no filme.

Buscaremos, então, as analogias possíveis dos trechos de música de Um condenado à morte escapou, com a estrutura do Kyrie, de Mozart. Além disso, se consideramos as obras do repertório clássico pré-existente utilizadas por Bresson em toda a sua filmografia, vemos um predomínio do período barroco, como os trechos de Lully, em Pickpocket (1959), de Monteverdi, em Mouchette (1967) e O diabo provavelmente (1977), de Purcell, em Uma mulher suave (1969), e de Bach, em O dinheiro (1983). De certa maneira, o Barroco também se faz presente na estrutura do Kyrie da Missa em dó menor de Mozart, tendo esta peça pertencido a um período em que o compositor austríaco entrou em contato com a obra de Bach. 
Observamos também que os trechos escolhidos do Kyrie representam momentos coletivos na música: o coro e a orquestra. Analisaremos, portanto, como a questão da "comunidade" se aplica ao filme já a partir da música.

Por conta de nosso assunto, teremos que fazer referência a termos do campo da Música. Embora isso possa tornar mais difícil a compreensão por parte de um público não especializado, consideramos fundamental em trabalhos aprofundados sobre música no cinema.

\section{Esquema geral e simetrias}

Um condenado à morte escapou se baseia na história da fuga de André Devigny (Fontaine, no filme) do forte Montluc, em Lyon, durante a Segunda Guerra Mundial. Publicada no Figaro Littéraire de 20 e 27 de novembro de 1954, foi depois lançada na forma de romance, em 1956.

Já o Kyrie é a primeira parte da missa cristã e seu verso Kyrie eleison (uma expressão em grego) significa "Senhor tende piedade de nós". No filme, os trechos dele advindos são utilizados apenas em nove momentos. No primeiro, durante os créditos, ouvimos o início do Kyrie, incluindo a entrada do coro. Nos três momentos seguintes, apenas a introdução instrumental acompanha as caminhadas dos prisioneiros. Na quarta vez, volta o coro - mas numa parte diferente daquela do início - num momento decisivo: é quando o prisioneiro Orsini tenta fugir. As três vezes seguintes, novamente instrumentais, referem-se respectivamente, a Orsini de volta à prisão após sua captura, a outra caminhada no pátio e à escolha do protagonista Fontaine quanto a levar ou não o companheiro Jost na sua fuga. O último momento, com o coro, é quando Fontaine e Jost, tendo sua fuga bem sucedida, afastam-se da prisão. Esquematizando todos os trechos num quadro, temos: 
Tabela 1 - Esquema geral dos trechos de música em Um condenado à morte escapou

\begin{tabular}{ccll}
\hline Trecho & Tempo & \multicolumn{1}{c}{ Parte da música } & \multicolumn{1}{c}{ Momento do filme } \\
1 & $0^{\prime} 17^{\prime \prime}-1^{\prime} 55^{\prime \prime}$ & Introdução instrumental + coro 1 & Créditos - imagem do muro \\
2 & $1^{\prime} 04^{\prime \prime}-19^{\prime} 27^{\prime \prime}$ & Introdução instrumental & Subida a partir do pátio \\
3 & $26^{\prime} 54^{\prime \prime}-27^{\prime} 15^{\prime \prime}$ & Introdução instrumental & Descida ao pátio \\
4 & $37^{\prime} 50^{\prime \prime}-38^{\prime} 12^{\prime \prime}$ & Introdução instrumental & Descida ao pátio \\
5 & $46^{\prime} 09^{\prime \prime}-47^{\prime}$ & Coro 2 (com interrupção) & Tentativa de fuga de Orsini \\
6 & $48^{\prime} 59^{\prime \prime}-49^{\prime} 21^{\prime \prime}$ & Introdução instrumental & Fontaine vê (de sua cela) Orsini sendo \\
7 & $58^{\prime} 08^{\prime \prime}-58^{\prime} 31^{\prime \prime}$ & Introdução instrumental & levado para fuzilamento \\
8 & $65^{\prime} 50^{\prime \prime}-66^{\prime} 07^{\prime \prime}$ & Introdução instrumental & Descida ao pátio \\
9 & $94^{\prime} 30^{\prime \prime}-96^{\prime} 15^{\prime \prime}$ & Coro 2 (inteiro) & $\begin{array}{l}\text { Na cela, Fontaine decide se vai levar Jost } \\
\text { em sua fuga }\end{array}$ \\
\hline
\end{tabular}

Como vemos, há um esquema geral bastante simétrico quanto ao uso de trechos de coro ou apenas instrumentais: coro (precedido da introdução instrumental) 3 partes instrumentais - coro - 3 partes instrumentais - coro. Além disso, o coro 2 vem aos 46 minutos de um filme de 96, ou seja, mais ou menos no meio. Já as partes instrumentais possuem intervalos de cerca de 20 e 25 minutos em relação aos coros do começo e do fim respectivamente, e, entre suas três repetições, intervalos de sete ou 10 minutos. Toda essa disposição dos trechos revela também uma simetria.

Com efeito, a simetria é base para várias formas musicais em geral, mas é fundamental no período do Classicismo, em que Mozart viveu, onde o equilíbrio da forma era um valor essencial.

Não sendo a música um simples suporte no filme, Bresson opta por silenciá-la quando o foco está nas ações principais do protagonista, deixando a ênfase nos ruídos. 
Isso explica o fato de que os maiores intervalos entre a utilização de trechos musicais estejam justamente no começo do filme (a tentativa frustrada de fuga) e no final (o processo da fuga bem sucedida).

Na verdade, Piva (2004) observa que Bresson pensara inicialmente em só utilizar a música nos créditos iniciais e no final, semelhante ao que fez, posteriormente, em O processo de Joana d'Arc (1962) e em Mouchette, o que teria sido uma opção ainda mais radical. Aspahan (2008) também associa a estrutura do filme ao Classicismo, porém não parte exclusivamente dos trechos musicais, como fazemos aqui, mas sim da simetria dos estados de Fontaine, ou seja, liberdade-prisão-liberdade, e das relações do espaço fixo da cela com espaços de mobilidade, como pátio e corredor. Assim, sugere que o filme teria quase que uma estrutura de rondó, forma bastante utilizada nos últimos movimentos de sonatas e sinfonias clássicas, marcada pela alternância de um tema A com outros: ABACAD.

A estrutura é simples e duplamente espiralar. Primeiro, no percurso do filme: liberdade-prisão-liberdade, tendo o elemento do trem e do Kyrie como início e fim. Segundo, pela estrutura interna dos espaços da prisão (cela, janela e banho - espaços fixos-, corredor e pátio lugares de passagem), que variam quase como num rondó, alternando o tema da cela com o dos outros espaços. Desse modo, a estrutura da filme como um todo é clássica, clara e concisa como uma sinfonia de Mozart."

(Aspahan, 2008, p. 55) 
Considerando agora os trechos de música no filme, teríamos ABAAACAAAC', sendo A correspondente ao trecho instrumental, B, a primeira entrada do coro, e C / C', o outro trecho de coro utilizado. Desta forma, se consideramos todos os trechos A juntos, poderíamos até aproximar a disposição dos trechos musicais no filme à forma rondó, como fez Aspahan em relação aos espaços. No entanto, o rondó normalmente está associado a andamentos rápidos, enquanto o Kyrie tem uma característica solene que é transmitida ao filme.

De todo modo, concordamos com Aspahan (2008) que o filme, de certa forma, termina como começou: com o coro e Fontaine em liberdade (na verdade, no início do filme, o protagonista acabara de ser preso; é preciso pensar que pouco antes do plano em que ele segue algemado num carro, estava em liberdade). Se considerarmos o esquema geral de Aspahan, liberdade-prisão-liberdade, podemos aproximar o filme da estrutura tripartita ABA, encontrada em muitas formas musicais.

O próprio Bresson sugere essa associação formal quando responde, numa entrevista, o porquê de ter suprimido os fatos que se passaram após a fuga do verdadeiro André Devigny:

Foi por uma simples razão de composição. Era necessário que o filme fosse redondo; devia começar ali e terminar ali. Caso contrário, poderíamos continuar ao infinito e contar as aventuras de Devigny na Argélia. Mas há exigências de composição, um ritmo a seguir, um momento em que se deve parar."

(Bresson, 1957, p. 8)

A palavra composição, utilizada reiteradamente pelo diretor em suas entrevistas, sugere também a aproximação com a composição musical e suas formas. 


\section{Analogias}

Em primeiro lugar, podemos já reconhecer uma semelhança entre a solenidade da missa de Mozart e a evasão do prisioneiro filmada como uma cerimônia. O próprio Bresson afirmou que a "cor" dessa missa lhe parecera com a cor do filme (Sémolué, 1993, p. 85).

Hocquard (1994) lembra que o dó menor do Kyrie, tom principal também da missa, foi relativamente raro na obra de Mozart como um todo, empregado apenas em grandes ocasiões. $\mathrm{O}$ autor considera essa tonalidade bastante trágica e sugestiva de uma ruptura que precederia uma libertação. Numa frase que nos faz pensar no percurso de Fontaine, afirma: "Este tom traz ao trágico um valor tônico, o de uma angústia ativa, aquém da esperança, mas que é já uma vitória sobre o desespero" (Hocquard, 1994, p. 178).

Além disso, o trecho instrumental inicial do Kyrie combina com as imagens dos prisioneiros andando como se estivessem numa procissão. Esse caráter de ritual é uma indicação presente no artigo e no livro de Devigny (1954, 1956, respectivamente), onde a fila dos prisioneiros é caracterizada como um cortejo solene, de ritmo lento, feito de ações repetitivas:

Em Montluc, no centro do corredor, nós nos reuníamos em silêncio: não tínhamos o direito de trocar uma palavra enquanto nos acorrentavam uns aos outros. Esta cena, embora bem simples e cotidiana, tomava para muitos um caráter solene [...]. Quando nossa triste coluna se desfazia,[...] era para pegar o caminho do Hotel Terminus, onde ocorriam os interrogatórios."

(Devigny, 1954, p. 1) 
Nós rodávamos em círculo no pátio. Nosso triste cortejo ia ao longo do barracão de madeira, passava sob as janelas da sala comum dos homens, desfilava diante do atelier e terminava o seu circuito perto do lavatório onde, a cada dez minutos, sob o sinal do Alemão, seis prisioneiros se precipitavam, tomando o lugar de seis camaradas que voltavam à sua fila."

Devigny, 1956, p. 60)

No pátio, nosso cortejo se desenrolava a cada dia sobre o mesmo ritmo triste e lento."

(Devigny, 1956, p. 75)

Ao mesmo tempo, com essa junção inusitada, sagrado e excrementos, Bresson realiza um oxímoro audiovisual (o oxímoro é uma figura de retórica caracterizada pela aproximação de opostos ou termos incongruentes). Aspahan também comenta esse aspecto:

Produz-se um choque entre o visual e o sonoro: a limpeza das fezes com a música sacra do Kyrie. O movimento dos prisioneiros em fila, cada qual com seus hematomas, manchas de sangue, roupas rasgadas, forma uma procissão de corpos vigilâmbulos."

(Aspahan, 2008, p. 57) 
Na verdade, mais do que "semelhança" ou "oxímoro", Bresson evoca o poder de transformação da música em contato com as imagens: "Em Um condenado à morte escapou, a Missa em dó de Mozart dá ao esvaziamento dos baldes no pátio da prisão um aspecto litúrgico que a imagem não tem" (apud Ajame, 1966).

A parte instrumental utilizada corresponde aos cinco primeiros compassos do Kyrie. Embora curto, é um trecho modulante, com cromatismos - que dão um efeito doloroso e expressivo (Nys, 1982) - e cheio de tensão, como convém a um filme em que o tempo todo se lida com o perigo da morte e em que se espera a fuga de Fontaine, anunciada já no título.

Observamos, na melodia, um movimento de descida (dó - sol - mi bemol - ré) e, depois, há uma subida em progressão ascendente. São movimentos análogos ao que acontece na imagem: por vezes, os prisioneiros descem ao pátio (trechos 3, 4 e 7), por vezes, sobem de volta às suas celas (trecho 2).

\section{Violino I.}

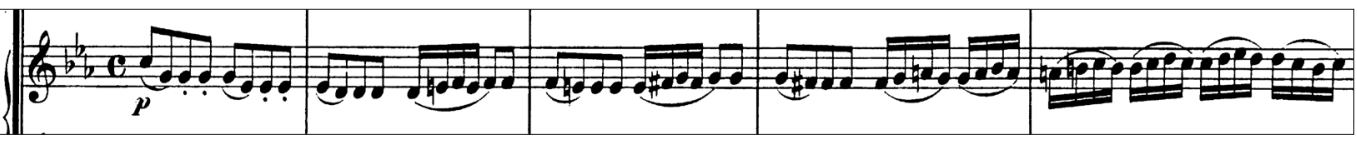

Figura 1 - parte dos primeiros violinos, cinco primeiros compassos do Kyrie (edições Breitkopf \& Härtel)

Dahan (2004) observa que a introdução instrumental teria uma função de abertura tanto no sentido musical quanto da diegese do filme: não apenas essas primeiras notas são por si só a abertura do Kyrie, como também traduzem a preparação de Fontaine para a sua fuga, as suas manobras para sair do encarceramento. Tal aspecto de preparação está na própria estrutura da música, no sentido de que os violinos precedem a explosão das vozes do coro (Dahan, 2004). 
Michel Chion (durante aula do curso Audio-vision, na universidade Paris 3, em abril de 2012), constata que, mesmo não se seguindo o coro, todas as vezes em que ouvimos a introdução instrumental, por reconhecimento do que já fora anunciado nos créditos, sentimos que algo está para acontecer. Numa análise semelhante, para Dahan (2004) as repetições da introdução instrumental do Kyrie ao longo do filme possuem uma função tanto mnemômica do topos da fuga (os muros a serem transpostos) como preditiva do seu sucesso.

Já Aspahan (2008) considera para o fato de ser a música nessas sequências puramente instrumental a possibilidade de que as vozes estariam guardando o último pedido de piedade para aqueles que ainda ficaram na prisão depois da fuga de Fontaine (além do pedido de piedade durante a fuga de Orsini, como analisaremos mais adiante).

Assim, o trecho instrumental está, na maioria das vezes, sobre as imagens dos presos em fila, funcionando como um estribilho. Para Aspahan (2008), a repetição é justamente a forma como "Bresson transforma a dureza da prisão num ritual constante, repetitivo, disciplinado, de tentar sobreviver ao massacre" (2008, p. 57). Assim, ela contribuiria para a "construção da rotina sonora da filme" (Aspahan, 2008, p. 57) e e nos ajudaria a "penetrar na monotonia do universo carcerário" (Douche, 1994, p. 67).

Observamos que o desenho rítmico desses primeiros compassos da música está presente ao longo de todo o Kyrie. Nys (1982) observa nele um caráter de litania, com "as repetições incessantes do texto, a resposta eleison confiada ao coro após um solo [...], a insistência na retomada do motivo feito de notas repetidas, o caráter implorante, suplicante, feito de cromatismos dolorosos" (1982, pp. 89-90). Portanto, a própria estrutura da música tematiza uma insistência tão repetitiva quanto os movimentos obstinados de Fontaine no trabalho de produção de sua fuga, assim como o caráter circular da roda dos prisioneiros no pátio. 
Em relação às partes do coro utilizadas, como vimos, não são as mesmas: nos créditos iniciais, está a primeira entrada do coro após a introdução instrumental, do compasso 6 ao 26; na parte central do filme, durante a fuga de Orsini, o trecho do coro utilizado é o que vem após o solo de soprano, do meio do compasso 71 ao meio do 91, com uma emenda para a cadência final do Kyrie, do meio do compasso 101 ao início do 103. No final do filme, é utilizada a mesma parte anterior, porém sem interrupção, indo até o final da música.

Observamos, assim, que Bresson, ao criar a trilha musical de seu filme a partir do Kyrie de Mozart, lança mão de duas características básicas da música: a repetição (dos trechos instrumentais) e a variação (dos trechos de coro).

Esses dois elementos são evocados no título do livro de Gilles Deleuze (1968), Diferença e repetição. Para Deleuze (1968), repetir não é simplesmente adicionar uma segunda vez a uma primeira, mas sim, elevar a primeira vez a uma potência infinita. Numa proposição de sentido também político, ele afirma que o princípio da repetição não é o do Mesmo, mas sim o do Outro, que compreende a diferença.

Também no campo da música, Jankélévitch (1983) observa que a repetição nunca é algo estéril, pois o intervalo de tempo entre as reproduções faz com que ela tenha um caráter de inovação, funcionando de uma maneira a fazer descobrir relações novas e, muitas vezes, exercendo um poder incantatório, tal como na litania considerada por Nys (1982).

Parece que Bresson estava consciente dessa potência: “Todos esses efeitos que você pode obter da repetição (de uma imagem, de um som)" (Bresson, 2008, p. 49). Com efeito, Um condenado à morte escapou é construído com base na repetição de gestos e da música, uma repetição que, no sentido deleuziano, contém também a diferença. 
Em relação às partes do coro, o professor Gianfranco Vinay (durante aula do curso Image musicale et dramaturgie sonore, na universidade Paris 8, em janeiro de 2012) observou, de forma espirituosa, que Bresson usa uma fuga para ilustrar outra fuga. Com efeito, no primeiro trecho de coro, após a entrada em defasagem de cada uma das vozes, há o início de uma fuga ${ }^{3}$.
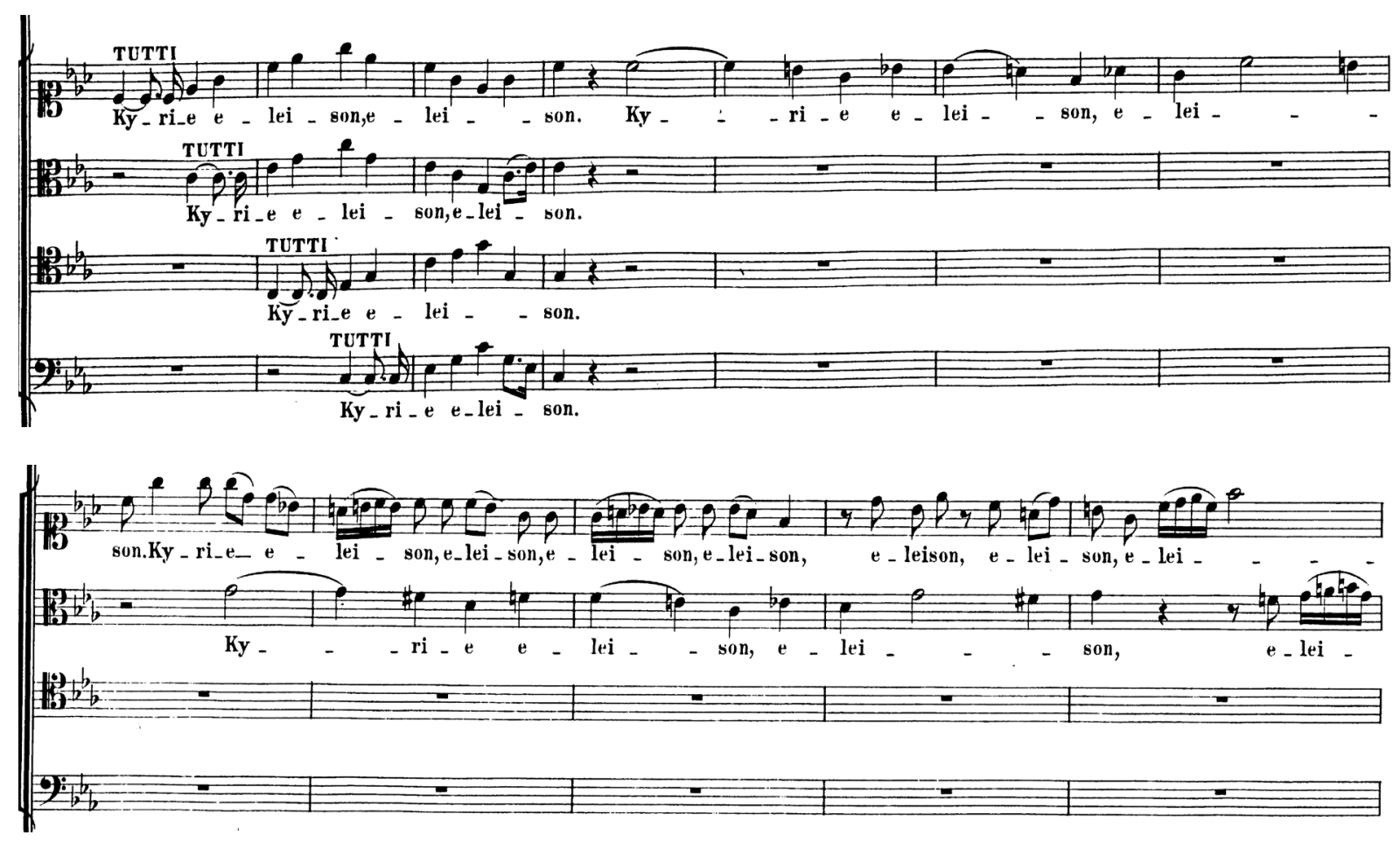

Figura 2 - Primeira entrada do coro: compassos 6 a 17 do Kyrie, parte vocal (edições Breitkopf \& Härtel). 
O contraste coro $X$ música instrumental é bastante comum na música do Classicismo. O coro tem um efeito de ampliar o espaço e isso é compatível com os momentos em que aparece: na abertura do filme, na tentativa de fuga de Orsini e na fuga de Fontaine e Jost. Em oposição a esses momentos de coro está a música instrumental sobre os prisioneiros confinados na prisão.

O primeiro trecho do coro se inicia no segundo plano do filme. No anterior, podíamos ver a letra cursiva do próprio Bresson sobre um plano geral da prisão, dizendo ser a história verdadeira e contada sem ornamentos. Então aparece, no segundo plano, uma placa em que está escrito: "Aqui sob a ocupação alemã sofreram dez mil homens vítimas dos nazistas. Sete mil sucumbiram", enquanto ouvimos os cinco primeiros compassos instrumentais.

A câmera faz uma panorâmica para a direita da placa, para um pedaço de muro, e, neste momento, começamos a ouvir o coro e a ler os créditos. Toda a parte do coro se dá sobre o muro, como se a abertura do espaço dado pelo crescimento da textura sonora e pelas vozes indicasse que esse muro será transposto.

A música termina junto com os créditos no tom de sol menor, num acorde de quinto grau, que transmite um efeito suspensivo 4 . Este acorde é comum à escala de ré maior, cujo modo (maior) confere um efeito de uma "luz no fim do túnel". De fato, nessas primeiras imagens do filme, encontramos referências não só à morte (os sete mil que sucumbiram), como também à fuga (o muro que Fontaine escalará no fim).

Em relação ao próximo trecho de coro, durante a fuga de Orsini, Sémolué (1993) observa que, neste momento, como indicado na segunda parte do título original do filme, "o vento sopra onde quer" (Le vent souffle où il veut) 5 , a roda da fortuna se movimenta. Orsini tenta a sua fuga no momento do esvaziamento dos baldes no pátio e o trecho musical utilizado começa com um desenho semelhante ao das partes 
instrumentais usadas nas outras sequências do pátio. No meio disso, as vozes do coro indicam que algo diferente vai acontecer.

Mas o pedido de misericórdia contido na letra do Kyrie não é ouvido no que diz respeito a Orsini e a música também dramatiza esse fato: Bresson interrompe o trecho - que tivera seu início modulante, como que num momento de esperança de fuga - e retoma o final da música, inexorável na conclusão no tom principal dó menor.

Assim, quando Fontaine e Jost conseguem finalmente fugir, o coro volta como um agradecimento. Nesse momento, Bresson usa o trecho completo e reforça que o pedido fora atendido. Para Dahan (2004) o coro assume aí uma característica vitoriosa, marcada pela ausência da introdução instrumental dos violinos, que, para a autora, estava mais próxima a uma súplica.

Além disso, como constata Piva (2004), aqui a música não concorre com os ruídos do ambiente nem com a voz de Fontaine: como o trecho dos créditos, esse momento de música leva o filme para outro espaço (e tal fato nos faz lembrar também da intenção inicial de Bresson de colocar a música só no começo e no fim).

\section{Coletividades}

Ao longo do filme, a música ocorre principalmente em momentos de impossibilidade de comunicação, pois, embora no pátio estejam todos juntos, os prisioneiros são proibidos pelos guardas de falarem entre si. Briot considera, então, que a música reforça ainda mais o silêncio de base do filme e o isolamento de Fontaine (Briot, 1957, p. 92). No entanto, veremos que os trechos do Kyrie não deixam de se referirem à "coletividade".

Com efeito, Bresson utiliza apenas trechos que contenham "momentos coletivos": a orquestra e o coro. Tal procedimento corresponde bem a um filme que trata da união e da solidariedade entre os presos. Só assim é possível sobreviver ali e fugir. De fato, a 
evasão de Fontaine só dá certo com a observação dos erros de Orsini em sua fuga mal sucedida e com a ajuda do companheiro de cela Jost.

A primeira vez em que ouvimos só o trecho instrumental (trecho 2 da Tab. 01) é depois que os prisioneiros tiveram um momento de "socialização" no lavatório, escamoteando a vigilância dos soldados para terem a oportunidade de dizerem seus nomes. A música começa quando retomam seus baldes e retornam às celas em fila, mas com um certo alívio pela possibilidade de contato. Junto com ela, a voz over de Fontaine diz: "O tempo de esvaziar nossos baldes e de jogar um pouco de água no rosto, voltávamos às nossas celas para mais um dia inteiro".

Já na segunda vez (trecho 3), a música é ouvida no momento da descida ao pátio. Junto com ela, não ouvimos a voz over de Fontaine, só o ruído dos passos arrastados, e o término do trecho coincide com o velho prisioneiro Blanchet caindo. Por um lado, a música termina com uma indicação da futura amizade - mais uma socialização entre Fontaine e Blanchet: o primeiro entrega ao companheiro o chapéu caído no chão. Por outro lado, pouco antes das primeiras notas do Kyrie, esta sequência começara com a troca de olhares entre Fontaine e Orsini. Além de ser uma confirmação da amizade entre os dois (com sua vigilância, Orsini ajudava Fontaine no processo da desmontagem da porta de sua cela), para Dahan (2004) já é uma indicação tópica importante da passagem do fracasso da fuga de um para o sucesso do outro.

A terceira vez (trecho 4) está também na descida ao pátio e no início da caminhada circular, mas a música está toda inserida em meio às conjecturas, feitas no comentário over de Fontaine, quanto às posições dos quartos dos guardas. Mais uma vez, mesmo sem as vozes do coro indicativas da evasão, esta já se faz anunciar pelas análises do protagonista. Segundo Dahan (2004), é importante também que, nessa sequência, a música comece mais longe da cela do protagonista e mais próxima da saída da prisão, ou seja, diante do quarto do guardião-chefe. 
A quarta vez (trecho 6), após a fuga e a captura de Orsini, é como uma tentativa de solidariedade pelo olhar que Fontaine lhe dirige de sua porta, aberta para a hora da refeição. Dahan (2004) salienta que a música marca aí a passagem do espaço físico da cela de Orsini para a de Fontaine: é mais uma vez o presságio do papel de um na fuga futura do outro, da "troca" entre eles. Nesse trecho não há a voz over do protagonista: ela se cala nesse momento de tristeza. Só ouvimos junto à música os ruídos: os passos de Orsini, os dos guardas, que o levam para a execução, a porta de Fontaine sendo fechada e o ruído da chave na sua ferradura. Se a porta fechada impede qualquer outro gesto de amizade entre os dois prisioneiros, ela confere a Fontaine um momento de reflexão: é como se as vozes caladas do coro fossem sua prece por Orsini.

Na quinta vez (trecho 7), durante a descida e a roda no pátio, junto com o ruído constante dos passos, a voz over de Fontaine faz várias considerações quanto ao aumento da coletividade carcerária e ao desaparecimento e surgimento de pessoas. Agora, a descida de Fontaine e seus companheiros se faz ao mesmo tempo em que há a subida de um outro grupo de presos: a coletividade é dividida, como numa tentativa de se mitigar sua força.

Já na última vez em que ouvimos o trecho instrumental (trecho 8), ele se dá no interior da cela de Fontaine. Mesmo assim há uma coletividade, embora reduzida: um novo prisioneiro, Jost, acabara de chegar para dividir a cela com o protagonista. As observações da voz over mostram as dúvidas quanto a levar o companheiro consigo na fuga (ou seja, aceitando a sua solidariedade) ou matá-lo.

Com efeito, Fontaine desconfia que Jost seja um espião. Nesse sentido, a chegada do rapaz poderia significar um eterno recomeço à preparação da fuga, o que, para Dahan (2004), poderia ser sugerido pelo fato de que o trecho de música é sempre o mesmo. Porém, vemos que, na verdade, a ajuda de Jost vai ser essencial para Fontaine. Portanto, nesse momento de música, mais uma vez, "o vento sopra onde quer". 
Dahan (2004) também observa que, diferentemente de Orsini, que age sozinho, Fontaine quer inclui-lo no seu plano de fuga, assim como ele o faz com Jost. A autora considera que o fracasso de Orsini pode ser inferido da própria música: afinal, o "seu comportamento contradiz totalmente a idéia de comunidade que o coro vocal representa" (Dahan, 2004, p. 102).

Na verdade, o Kyrie tem uma seção intermediária - Christe eleison ("Cristo, tende piedade de nós") - com um solo de soprano, que Bresson não utiliza, confirmando a sua escolha de momentos coletivos da música. Talvez também porque essa parte seja por demais radiante em sua tonalidade de mi bemol maior, que, segundo Hocquard (1994), representa a resolução da angústia na graça. Mesmo no final do filme, quando Fontaine e Jost "recebem a graça" de fugir da prisão, Bresson prefere utilizar o coro, terminando em dó menor, pois os outros prisioneiros continuam em suas celas.

Como observa Joel Magny (1983), o herói bressoniano - e Fontaine não é uma exceção - está normalmente encarcerado em si mesmo (ele próprio, uma prisão). Nesse sentido, o que Fontaine descobre ao longo do filme é a relação com o outro. Também para Cunneen (2003), o filme (e acrescentemos, a sua própria música) tematiza o movimento da solidão para a comunicação.

Desta forma, no início do filme, Fontaine chega à prisão e é colocado sozinho numa cela. De lá, consegue falar com um homem no pátio, que lhe passa papel e lápis (a possibilidade de contato com o exterior), além de usar o som de seus punhos batendo na parede para se comunicar com o preso da cela ao lado. Em outra cela, Fontaine vai, aos poucos, quebrando os receios do vizinho Blanchet, com quem passa a conversar à janela e estreitando os laços de amizade. O pátio é um local em que todos os presos estão juntos, embora a comunicação entre eles seja proibida, mas esta é conseguida no lavatório, onde o ruído da água a encobre, permitindo que os prisioneiros troquem 
ideias e planos de fuga (como Orsini e Fontaine). Finalmente, há a chegada de Jost à cela de Fontaine e a fuga dos dois.

Falando-se em comunicação e comunidade, lembremos que há toda uma discussão em relação à última no campo da filosofia por autores como Maurice Blanchot, JeanLuc Nancy e, mais recentemente, Giorgio Agamben. Tanto Nancy como Blanchot ${ }^{6}$ partiram dos estudos de Georges Bataille e respondem-se um ao outro em seus textos. Acreditamos que a "comunidade" dos presos de Um condenado à morte escapou pode ser, de certa forma, entendida à luz das ideias de Blanchot (1983).

O autor considera que a relação dos homens entre si é essencialmente assimétrica, pois não se constitui numa relação com o Mesmo, mas sim, com o Outro. A comunidade é, portanto, uma tensão, uma solidão partilhada, como podemos observar na comunidade dos homens isolados em suas celas em Um condenado à morte escapou. E, pensando-se também na música coral e instrumental do filme, cada voz, cada instrumento é uma singularidade em sua diferença, mesmo estando em uníssono.

Em relação à partilha de um segredo, Blanchot observava que: "o mais pessoal não podia ser guardado como um segredo próprio a um único, pois ele rompia os limites da pessoa e exigia ser partilhado" (1983, p. 37), tal como os segredos partilhados entre os presos, arriscando-se sob a vigilância dos soldados.

Para Blanchot, partilha-se também a solidão da morte do outro, não só para ajudá-lo a morrer, mas

Me manter presente na proximidade do outro que se afasta definitivamente ao morrer, tomar para mim a morte do outro como a única morte que me concerne, eis aquilo que me coloca fora de mim e é a única separação que pode me abrir, na sua impossibilidade, ao Aberto da comunidade."

(Blanchot, 1983, p. 21) 
Pois, é ao morrer, que Orsini transmite a Fontaine o segredo da possibilidade da fuga, o que, por sua vez, torna possível a experiência do impossível por parte de toda a comunidade de presos. Como vimos, a relação entre Fontaine e Orsini está também na música: a parte que se calara durante a morte de Orsini é transmitida a Fontaine durante sua fuga.

Se, neste final, quando Fontaine e Jost fogem juntos e ouvimos o coro do Kyrie, tudo contribui para um êxtase, palavra que nos leva imediatamente a Bataille, não se deve pensar numa união fusional dos dois fugitivos. Para Blanchot (1983), o êxtase é o "fundo sem fundo da comunicação", ou seja, há comunidade, mas sem fusão, é uma comunidade inconfessável.

\section{Mozart, o Classicismo e o Barroco}

Quanto a uma certa preferência de Bresson em relação ao período barroco nas escolhas musicais ao longo de sua filmografia, podemos observar que, embora Mozart seja um compositor do Classicismo, em seu Kyrie da Missa em dó menor K427 há a utilização de técnicas bastante desenvolvidas no Barroco, como o contraponto. Este é percebido, por exemplo, na primeira entrada do coro. De fato, vários musicólogos discutem se não haveria uma influência considerável do Barroco sobre Mozart na época da composição dessa peça.

Mozart a escreveu em 1782-1783, quando, já estabelecido em Viena, tocava com regularidade na casa do Barão Gottfried van Swieten, que havia sido embaixador em Berlim. Van Swieten tinha uma predileção por música barroca antiga, dificilmente ouvida na Viena da época de Mozart.

Diferente do que acontece atualmente - em que a preferência das salas de concertos é para compositores de 200 anos atrás -, nos séculos passados, a música ouvida e apreciada era a do presente: Johann Sebastian Bach já era, na época de Mozart, um 
compositor "antigo", no sentido de "ultrapassado". É fato que a música de Bach ficou durante muito tempo esquecida pelo público em geral, tendo sido reabilitada só por Mendelsohn, no início do século XIX.

Sadie (1988) observa que, após o contato com Van Swieten, Mozart copiou fugas de Bach. Algumas de suas obras dessa época refletiriam a resposta do compositor clássico austríaco ao desafio da técnica barroca7 ${ }^{7}$.

De fato, esta missa não foi escrita por encomenda - o mais comum na época -, mas sim como um agradecimento pela saúde de Constanze Weber, com quem o compositor se casou ${ }^{8}$. Isso poderia explicar uma maior liberdade de Mozart em sua composição, por exemplo, as grandes dimensões das partes (Nys, 1982, p. 88).

Porém, Sadie (1988) argumenta que, embora esta missa possua "um certo sabor arcaico", ela não teria uma diferença significativa do modelo eclesiástico austríaco tradicional. Nys (1982) observa que, em meados do século XVIII, havia na música religiosa uma predominância do stile misto, ou seja, "da conjugação de elementos provenientes da polifonia antiga, 'severa' e contrapuntística, e aqueles do novo cantabile da melodia harmonizada" (Nys, 1982, p. 4). Sadie (1988), porém, afirma que a obra - deixada, aliás, incompleta (o Credo só vai até o versículo Et incarnatus est e falta o Agnus Dei) - foi bastante criticada pelo seu suposto estilo inconsistente.

De qualquer forma, independentemente da influência de Bach ou não em Mozart, nota-se a presença de técnicas do Barroco no trecho escolhido por Bresson da Missa em dó menor K427. Além disso, o oxímoro, figura de retórica que identificamos na utilização do trecho do Kyrie sobre as imagens dos prisioneiros com seus baldes de detritos, foi uma figura-chave na literatura barroca, dentro de um movimento que se caracterizava pela dualidade, pelos contrastes. 


\section{Conclusão}

Observamos que, no filme Um condenado à morte escapou, o diretor Robert Bresson imprime uma marca de autoria quanto à música, como no conceito de Gorbman, (2007), assumindo o controle da trilha musical do filme ao utilizar somente trechos do Kyrie da Missa em dó menor K427 de Mozart.

Bresson se preocupou com a simetria, característica das obras do Classicismo do próprio Mozart, e lançou mão apenas de trechos coletivos de coro e orquestra. Tal aspecto de comunidade convém a um filme sobre uma fuga que só é bem sucedida pela comunicação com o Outro, pelo trabalho coletivo.

Como se fosse um compositor, Bresson se valeu de elementos básicos das formas musicais: a repetição (pela utilização constante dos mesmos cinco compassos instrumentais da introdução do Kyrie) e a variação (com o uso de diferentes partes do coro).

\section{REFERÊNCIAS}

AJAME, Pierre. Le cinéma selon Bresson. Les Nouvelles Littéraires, 26 mai. 1966.

ASPAHAN, Pedro. Entre a escuta e a visão: o lugar do espectador na obra de Robert Bresson. 2008. Dissertação (Mestrado em Comunicação Social) - Universidade Federal de Minas Gerais, Belo Horizonte, 2008.

BLANCHOT, Maurice. La communauté inavouable. Paris: Minuit, 1983.

BRESSON, Robert. Propos de Robert Bresson. Cahiers du Cinéma, n. 75, pp. 3-9, out. 1957.

. Notas sobre o cinematógrafo. São Paulo: Iluminuras, 2008.

BRIOT, René. Robert Bresson. Paris: Les Éditions du Cerf, 1957.

CUNNEEN, Joseph. Robert Bresson: a spiritual style in film. New York: The Continuum International Publishing, 2003.

DAHAN, Danielle. Robert Bresson: une téléologie du silence. Heidelberg: Universitätsverlag Winter, 2004.

DELEUZE, Gilles. Différence et répétition. Paris: Presses Universitaires de France, 1968.

DEVIGNY, André. Un condamné à mort s'est échappé. Figaro Littéraire: 20 nov. 1954 e 27 nov. 1954. 
DEVIGNY, André. Un condamné à mort s'est échappé. Paris: Gallimard, 1956.

DOUCHE, Sylvie. Robert Bresson: de la musique à l'ineffable. Diplôme d'Études Approfondies (DEA) de Musique et Musicologie. Paris IV, 1994.

GORBMAN, Claudia. Auteur music. In: GOLDMARK, Daniel, KRAMER, Lawrence, LEPPERT, Richard (org.). Beyond the soundtrack: representing music in cinema. Los Angeles: University of California Press, 2007. HOCQUARD, Jean-Victor. Mozart. Paris: Seuil, 1994.

JANKÉLÉVITCH, Vladimir. La Musique et l’Ineffable. Paris: Seuil, 1983.

KENYON, Nicholas. Mozart: vida, temas e obras. Lisboa: Edições 70, 2008.

MAGNY, Joel. L'expérience intérieur de Robert Bresson. Cinéma, n. 294, Dossier Robert Bresson, jun. 1983.

NYS, Carl de. La musique religieuse de Mozart. Paris: Presses Universitaires de France, 1982.

PIVA, Manlio. L'inquadratura sonora: immagine e suono in Robert Bresson. Padova: Esedra, 2004.

SADIE, Stanley. Mozart. Porto Alegre: L\&PM, 1988.

SÉMOLUÉ, Jean. Bresson. Paris: Flammarion, 1993.

ZAMARCOIS, Joaquim. Curso de formas musicales. Barcelona: Editorial Labor, 1994.

\section{Referências audiovisuais (em ordem cronológica)}

Um condenado à morte escapou (Un condamné à mort s'est echappé ou Le vent souffle où il veut). Robert Bresson, França, 1956.

Pickpocket. Robert Bresson, França, 1959.

O processo de Joana d'Arc (Le procès de Jeanne d'Arc).Robert Bresson, França, 1962.

A grande testemunha (Au hasard Balthazar). Robert Bresson, França / Suécia, 1966.

Mouchette, a virgem possuída (Mouchette). Robert Bresson, França, 1967.

Uma mulher suave (Une femme douce). Robert Bresson, França, 1969.

O diabo provavelmente (Le diable probablement). Robert Bresson, França, 1977.

O dinheiro (L'argent). Robert Bresson, França, 1983.

\section{NOTAS}

1 Este artigo foi apresentado na conferência Avanca Cinema, em Avanca, Portugal, em julho de 2012. Esta é a versão revisada. 
2 Bresson conheceu a história de Devigny por meio do artigo do Figaro Littéraire, que termina, como no filme, com a fuga da prisão, mas, no romance, o relato continua para além da fuga. A resposta de Bresson e outros aspectos nos mostram que o diretor já tinha conhecimento do romance, escrito na época da rodagem do filme. Devigny atuou, inclusive, como conselheiro no set. Tradução nossa, assim como as demais citações em língua estrangeira presentes no artigo.

3 Forma musical polifônica bastante utilizada no período barroco e caracterizada pelo uso da técnica do contraponto.

4 A frase musical é suspensiva quando não dá uma sensação de final absoluto, mas sim de um descanso provisório que necessita de uma continuação. É o caso da frase terminando na harmonia do quinto grau da escala. Já a frase conclusiva termina no primeiro grau da escala (Zamarcois,1994).

5 Palavras contidas no Evangelho de São João, no bilhete dado pelo pastor a Fontaine. Há, nelas, também uma menção às ações da predestinação e da graça, comumente associadas à heresia do Jansenismo, a que muitos autores costumam associar Robert Bresson. Por outro lado, apesar dessa referência à Bíblia, Cunneen (2003) observa que nada chama a atenção na vestimenta e/ou no aspecto do personagem do pastor para a sua atividade religiosa, tal como aliás, Bresson fez questão de representá-lo.

6 Deve-se entender os estudos de Blanchot e Nancy como uma resposta quanto à possibilidade de uma comunidade após a derrocada do Comunismo. No filme de Bresson, o contexto é outro, o do Nazi-fascismo, cuja comunhão fusional numa totalidade trans-individual é rejeitada pelos dois autores (e Blanchot, diferente de Nancy, não vê em Bataille a defesa da comunhão fusional).

7 Na verdade, Mozart já tinha tido contato com a técnica do contraponto no seu convívio com o padre Martini, em Bolonha, por ocasião da viagem que fez com o pai à Itália, em 1770.

8 Em carta ao pai, datada de 14 de janeiro de 1783, Mozart escreveu: “Fiz uma promessa a mim próprio, do fundo do coração, e espero ser capaz de a manter. Quando a fiz, a minha esposa ainda estava solteira; no entanto, como eu já pretendia casar com ela, após a sua recuperação, foi uma promessa fácil de fazer. A partitura de metade de uma missa que ainda tenho aqui à espera de ser terminada, é a melhor prova da promessa que fiz" (Kenyon, 2008, p.253).

Recebido em: 03 jul. 2013

Aceito em: 05 mar. 2014

\section{Endereço do autor:}

Luíza Beatriz Amorim Melo Alvim <luizabeatriz@yahoo.com>

Universidade Federal do Estado do Rio de Janeiro - UNIRIO

Av. Pasteur, 296 - Urca

22290-240 Rio de Janeiro, RJ, Brasil 